\title{
Urban Resilience in Addis Ketama and Lideta Sub Cities of Addis Ababa: The Case Tekilehaimanot Area Addis Ababa, Ethiopia
}

\author{
Mesfin Assefa \\ Ethiopian Institute of Architecture, Building Construction and City Development, Addis Ababa University, Addis Ababa, Ethiopia \\ Email address: \\ mesfinassefa491@gmail.com \\ To cite this article: \\ Mesfin Assefa. Urban Resilience in Addis Ketama and Lideta Sub Cities of Addis Ababa: The Case Tekilehaimanot Area Addis Ababa, \\ Ethiopia. Urban and Regional Planning. Vol. 3, No. 2, 2018, pp. 44-54. doi: 10.11648/j.urp.20180302.12
}

Received: May 24, 2018; Accepted: July 9, 2018; Published: August 15, 2018

\begin{abstract}
The city of Addis Ababa is experiencing wide range of changes in terms of physical, socio-economic, and environmental aspects. Its administration has implementing various programs to re-structure and to create resilient city. However, empirical researchers argue that despite remarkable achievements in restructuring of the city to make it more livable, there are several and complex urban downsides and bottlenecks. With this regards, this study is conducted to identify the resilience of sampled residents in Teklehayimanot areas of Addis Ababa city using cognitive mapping strategy. The study is carried out taking a case study of specific area of Teklhayimant District in which three specific sites are randomly selected from the district. From these three different sites, three informants are randomly selected from each specific site. The research has pursued a qualitative research approach substantiated by descriptive research design to analyze and interprets data. To gather pertinent data from respondents, the research has employed in-depth interview, observation and document analysis tools. Besides, secondary data are generated from literature through review of documents. The findings of the study indicate that respondents had almost similar understandings of their surroundings in terms of the socio-economic values. It is discovered that respondents observe the social, economic, and physical changes in their respective area closely and that the restructuring processes are perceived as it bears impacts on their physical, socio-economic lives. Two of the respondents argued that the reconstruction and re-establishment efforts that the city administration conducts in the area are significantly harming the social, economic, and physical conditions of the residents while the other respondent stated that the change are important as far as they are planned and reserve the social and economic bonds of the society. In general, the cognitive mapping portrayed by respondents from three different localities of the study area indicates that respondents are highly affiliated to the living condition they are leading. It indicates that the city administration efforts of re-structuring of the area must integrate all scope of resilience, as the residents are exceedingly worried about their firmed economic and social existence. In addition, it is suggested that the range of instruments including effective communication, participatory approach, and integrative urban development framework will help the city administration to its concerns to make the city more resilience. This will also bring opportunities to manage the change in well-organized manner.
\end{abstract}

Keywords: Neighborhood, Urban, Resilience, Mapping, Cognitive, Re-construction, Construction

\section{Introduction}

This paper is the result of a mini-research conducted on a cognitive mapping of randomly selected informants in Addis Ababa City Teklehaimanot district on the resilience of informants living areas. The purpose of the study is to understand the resilience situation of the study areas in terms of physical, socio-economic, and environmental aspects using cognitive mapping techniques. As the study areas are old settlements, poorly planned and are currently under reconstruction process, there are resilience problems observed among residents. With this regards, the research employed qualitative research approach aided with descriptive research design in order to investigate, analyze and present the informants ${ }^{\text {ee }}$ idea about urban resilience of the sites in which the respondents portrayed in their cognitive mapping process. 
The paper has four major parts. The first part presents the background, justifications and objective of the study. In addition, it talks about the research questions and description of the study area. Research methodology is discussed in part two while the third part discusses the findings of the study. Finally, the fourth section expresses the conclusion of the study.

\subsection{Background of the Study}

In recent urban development scenarios, the concept of resilience has been applied to that of cities by researchers, urban planners and local governments a like [1]. In this context, resilience indicates the ability of a system, community or society exposed to change to resist, absorb, accommodate and recover from the effects of a change in a timely and efficient manner, including through the preservation and restoration of its essential basic structures [2]. It is the capacity and ability of a community to withstand stress, survive, adapt, bounce back from a crisis or disaster and rapidly move on. Resilience needs to be understood as the societal benefit of collective efforts to build collective capacity and the ability to withstand stress [3] (As ICLEI 2012 p.5 cited in) [1]. Subsequently, urban resilience refers to learning, planning, forecasting, resisting, absorbing, accommodating to and recover from unforeseen changes within cities (As Jabareen 2012 cited in) [1]. This implies that a resilient community is one that can absorb disturbances, change, reorganize and then still retain the same basic structures and provide the same services [2].

Dominantly, in the twenty-first century, urban areas are in a constant process of internal and external change: they decline or expand, developing new form and function, dealing with various difficulties such as segregation, changing demographics and spatial patterns, economic crisis and global competition (Marcuse and van Kempen, 2000 cited in) [1]. Urban centers never fully enter a state of stability, and keep on shifting causes, appearances, scales and effects (Marcuse and van Kempen, 2000 cited in) [1]. This makes urban resilience efforts a difficult task to achieve. As established fact, cities especially in developing countries have always faced risks, and many cities that have existed for centuries have demonstrated their resilience in the face of resource shortages, natural hazards, and conflict [3]. With this regards, the very features that make cities feasible and desirable their architectural structures, population concentrations, places of assembly, and interconnected infrastructure systems also put them at high risk to (expansion compacted housing and slum areas, low access and quality roads, absence of green areas, traffic congestion), floods, earthquakes, hurricanes,.... This requires advance planning and action to reduce those risks through the development of resilient cities [4].

In Ethiopia, it is estimated that more than 20 percent of the total population of the country currently lives in urban areas, which has rendered it as one of the least urbanized countries in Sub-Saharan Africa. Despite this low level of urbanization, however, the country has one of the higher rates of urbanization even by the standards of developing countries, which is estimated at 4.1 per cent [5]. However, in the country, the mechanisms employed to manage this rapid rate of urbanization by the government and establish a resilient urban development is compounded by diversified socioeconomic and environmental challenges. This situation is empirically evidenced in Addis Ababa City as one of the highly expanded city in the country.

The city is characterized by a higher rate of horizontal expansion especially in the past two decades. Such expansion compounded with absence of well-integrated city development planning made the city face multiple socioeconomic, engineering, and environmental challenges. According to Office for the Revision of Addis Ababa Master Plan basic services (like telecommunication, media, roads, hotels, education and health) and such facilities as recreational centers in Addis Ababa hardly meet the standards provided by other competitive African cities. Addis Ababa has increasingly been expanding haphazardly and horizontally along the five regional outlets [6]. Furthermore, according to Alebel and Genanew Addis Ababa City is characterized by deteriorating environmental conditions and limited economic development [7]. The spatial, physical and socio-economic condition of Addis Ababa City, in general, is by far behind the requirements fundamental to sustain the livelihood of the City`s population. The City is faced with many challenges and it requires embarking on sustainable development efforts - actions that brings development reinforced by protection of the environment [7]. The limitations of its current developmental trend and the depth of the existing environmental problems, coupled with the requirements of the projected population of about ( 5 million people by the year 2017), entail reexamination of constraints and opportunities with the aim of devising appropriate measures and strategies for action [7].

In Addis Ababa, there are continuous and visible internal and external changes, which have impacts on the resilience of the city in terms of its livability and adaptation of the residents to these changes [8]. Furthermore, Mehret argued that Addis Ababa is a fast growing urban center that is beset with problems afflicting most cities in the developing world, including extensive urban poverty, joblessness, inadequate housing, severe overcrowding and congestion and undeveloped physical infrastructure [8]. Consideration this, the research will look into the city resilience situation in Addis Ababa city by taking a few cases in one of the specific district of Teklehayimanot area. In order to conduct the research, the researcher has employed simple random sampling technique to identify specific research sites. Accordingly, it tried to look into the resilience of the research site in a specific area of Koche, Gola Number One and Gola Number Two within Teklehaimanot district through the aid of cognitive mapping of the informants. Cognitive mapping in this context is a mental picture or image of the layout of one's physical environment. It provides a model or map of peoples ${ }^{\text {ee }}$ environment that they can use [9]. It also makes it easier to recall information, such as directions to our house 
and assist people in learning information. In this study, cognitive mapping technique is thus employed as it provides a framework that enables the researcher gain relevant information about the study areas ${ }^{\text {ee }}$ resilience situation through the aid of cognitive mapping in which informants portray their physical and social environment at its natural setting. This will also help to identify how residents/informants perceive and understand their surrounding situation.

\subsection{Justification of the Study}

As the 21 st century unfolds an increasing majority of the world's population lives in cities. Human wellbeing in cities relies on a complex web of interconnected institutions, infrastructure and information [3]. People are drawn to cities as centers of economic activity, opportunity, and innovation. However, cities are also places where stresses accumulate or sudden shocks occur that may result in social breakdown, physical collapse, or economic deprivation [3]. Resilience in this sense is a term that emerged from the field of ecology in the 1970s, to describe the capacity of a system to maintain or recover functionality in the event of disruption or disturbance [3]. It is applicable to cities because they are complex systems that are constantly adapting to changing circumstances. The notion of a resilient city becomes conceptually relevant when chronic stresses or sudden shocks threaten widespread disruption or the collapse of physical or social systems. The conceptual limitation of resilience is that it does not necessarily account for the power dynamics that are inherent in the way cities function and cope with disruptions [2, 3].

As a concept, resilience can be specifically applied to any community and any type of disturbance: natural, man-made, or a combination of the two [3]. Disaster resilience can be seen as a public good that builds an appropriate amount of redundancy into urban systems and encourages communities to plan for dealing with disruptions [2].

Resilience focuses on enhancing the performance of a system in the face of multiple hazards, rather than preventing or mitigating the loss of assets due to specific events [10,3]. In order to gain resiliency, cities need to be adaptable in the sense that they need to be able to withstand and adjust to disruptions [1]. Urban resilience is not only about surviving potential risks and threats, but also about grasping the positive outcomes these changes and transformations might bring. Urban planners and other involved actors such as policymakers and local governments play an important role within the shaping of resilient cities [10].

Many Ethiopian cities are vulnerable to shocks such as flooding, fire, and earthquakes that can disrupt cities and undermine development gains. For example, in April 2016, a rainstorm caused serious infrastructure damage in Dire Dawa city, which is regularly exposed to flooding. In Addis Ababa, in 2012 a fire in a five-story building in Efoyta Market caused damages amounting to ETB 20 million (US\$1 million). All regional capitals have experienced deadly floods that have also led to casualties and left expensive reconstruction needs. Climate change is likely to make future shocks more intense and frequent [11]. These shocks and stresses have the potential to bring cities to a halt and reverse years of socio-economic development gains. Cities that are to grow and thrive in the future must take steps to address these shocks and stresses. Simply put, a resilient city is one that can adapt to these types of changing conditions and withstand shocks while still providing essential services to its residents. A resilient city can keep moving toward its longterm goals despite the challenges it meets along the way [12].

Ethiopian Government is taking steps to reduce cities vulnerability and to realize its urban development vision to "Create resilient and livable cities". The National Urban Development Spatial Plan (NUDSP) and the Ethiopian Cities Sustainable Prosperity Goals (ECSPGs) recognize resilience as a key pillar for development of Ethiopian cities. Recognizing the need to identify concrete priority actions and investments, with the help from the World Bank, the Government has initiated a strong engagement process with stakeholders from all nine regional capitals and the Dire Dawa city administration [11]. In light of the above theoretical and empirical understandings, researchers that illustrate the resilience of the study areas using cognitive mapping strategies could have a positive impact in understanding the situation in which respondents are living. Besides, it will help in creating a more resilient and livable surrounding for the people. Hence, this research will inquire into the resilience process in Teklahaimanot area of Addis Ababa city by using cognitive mapping strategies. In this context, there is a popular view that people's mental representations of environments are embodied in cognitive maps. It is understood that cognitive maps are map like mental constructs that can be mentally inspected [9]. Hence, the study will employ cognitive mapping strategies to address the resilience level in Teklehayimanot area of Addis Ababa city. To this end, the major objective of the study is to examine the cognitive mapping of informants in order to understand the resilience of the study area.

\subsection{Objectives of the Study}

\subsubsection{General Objectives}

The general objective of the study is examining the resilience situation of the study areas in terms of socioeconomic and environmental aspects using cognitive mapping techniques.

\subsubsection{Specific Objectives}

The following are the specific objectives of the research

1. To identify the responses of government towards making the study areas more resilient.

2. To forward possible conclusions and implication (if any) in order to create a more resilient city for the residents in the study areas.

\subsection{Research Questions}

The research is going to address the following research questions 
1. What is the resilience situation of the study area in terms of the socio-economic and environment aspects?

2. What are the strategic responses of government towards making the study areas more resilient?

3. What could be the possible conclusions and proper recommendations of the study in order to create a more resilient city for the residents in the study areas?

\subsection{Description of the Study Area}

Addis Ababa, its capital, was established in 1886 during the reign of emperor Menelik II, is with altitude range 2000$2500 \mathrm{~m}$ above sea level, and annual average temperature is between 5 and $27^{\circ} \mathrm{C}$ and about $1175 \mathrm{~mm}$ annual rainfall on average. From the time of its foundation Addis Ababa is serving as a seat for Government and center for economic, political, cultural and many other social services. Concerning the population, it hosts an estimated 3.238 million people, which is a $17 \%$ share of Ethiopia's total urban population. Currently, Addis Ababa is experiencing an annual growth rate of $3.8 \%$ and is estimated to reach 4.7 million inhabitants by 2030 [13]. The main reason for this number and its continuous increase is the rural urban migration. The city's birth_and death rate accounts for $22.30 \%$ and $7.3 \%$ respectively and this have also significantly contributing for the increase. The city administration with the intension of properly addressing the multifaceted problems, and establish a more resilience city administration has introduced improved decentralized governance in 2002 by reforming the administrative structure of the city by proclamation number $361 / 95$ which was issued to divide the city administration into Ten Sub-Cities. These include the Lideta, Addis Ketema, Gulele, Yeka, Arada, Kolfe, Kirkos, Bole, Nefasilk-Lafto, and AkakiKaliti. Dividing itself in to these 10 sub-cities, the city administration has played and is playing a great role in solving physical, economic, social and environmental problems. From the sub cities listed above, the concern of this paper is on Lideta and Addis Ketemasub-cities with special focus on the Teklehaymanot district.

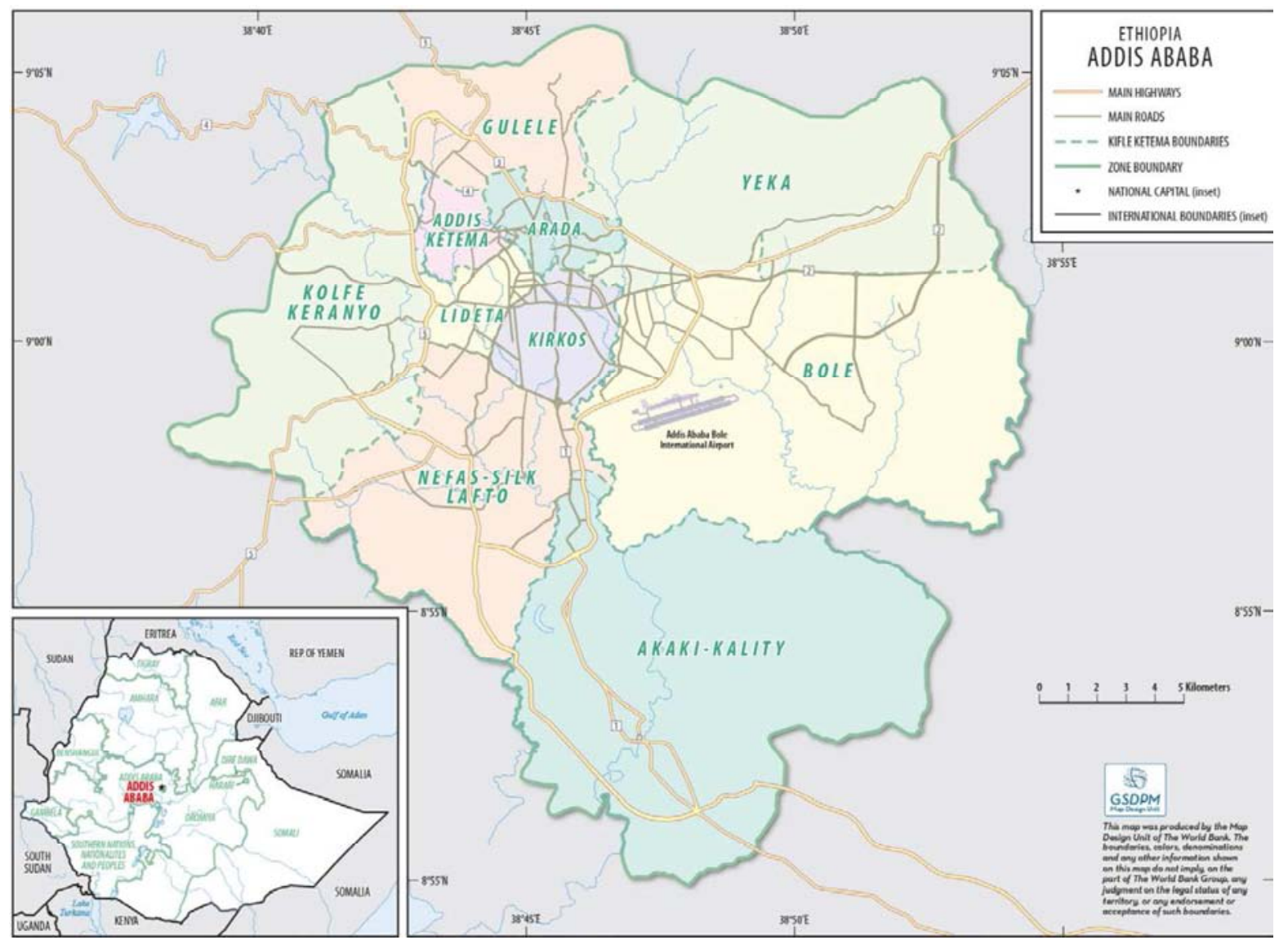

Figure 1. Metro area of Addis Ababa.

\section{Methodology of the Research}

\subsection{Research Design}

The entire strategy of the study is designed descriptively. This strategy is followed in order to examine the resilience situation of the study areas in terms of socio-economic and environmental aspects using cognitive mapping techniques. Data gained from randomly selected informants is analyzed and presented in descriptive research design. This design helps to describe situations, events, and activities in their natural setting, as they exist. Hence, the primary reason descriptive research design is employed is that it has the potential to address the objectives of the study. This helps the researcher to identify and describe the urban resilience 
situation of the study site as it exists based on the cognitive mapping of informants. Besides, qualitative research approach is assumed in the research to substantiate the research process.

\subsection{Sources and Types of Data}

To undertake this study, both primary and secondary data are utilized. The data gained from randomly selected informants and observation to the sites of the study represents the primary data. Secondary data from relevant literature is made by assessing relevant documents from different sources that elucidate the concept of resilience and cognitive mapping. Besides, the research mainly utilizes qualitative type of data.

\subsection{Instruments of Data Collection}

To undertake this research work, primary data will be extracted and used by using appropriate common study tools and instruments including in-depth interviews, drawings made by respondents and direct observation to the study sites. In addition, document analysis from secondary data is utilized.

\subsection{Data Analysis and Interpretation Methods}

The collected data is analyzed and interpreted in accordance with qualitative research approach that involves logical interpretation of interview results and content analyses of documents. In doing this, data editing, compiling, and analysis of all verbal discussion are qualitatively made. In the interpretation part, descriptive type of interpretation is used and presents the findings of the study accordingly.
Two types of sampling techniques are utilized in the study. Primarily, simple random sampling is employed in order to select representative study site within Addis Ababa city administration. Hence, the study target area, which is Teklahayimanot district, is selected randomly. The study district has around 10 Kebele or local administrations. Using stratified sampling techniques, these localities are arranged in three strata or categories based on the homogeneity nature of the localities in terms of economics and social activities and patterns of settlements. In order to select representative sites from the three strata, a simple random sampling technique is used and three specific areas are identified. To this end, one specific study site is selected from each stratum randomly. Hence, three sample areas namely Koche, Gola number One and Gola number Two within Teklahayimanot area are randomly selected. Besides, one informant from each specific area is selected randomly. Informants are selected randomly because this technique gives equal opportunity to the people living the study areas to participate in the study and informants are selected independent of the influence of one another. After selecting informants has done, the researcher approached informants by providing them precise information about the researcher, his research objectives, and assured informants about the confidentiality of their interview as it is used only for academic purposes [14]. Finally, the researcher presented questions for informants about informants ${ }^{\text {ee }}$ physical, social, economic and environmental living situation. In addition, the researcher has also investigated the government efforts to restructure the surrounding physical layout and its impacts on the informants $^{\text {ee }}$ resilience. The following figure illustrates the three localities, which are selected for the study

\subsection{Sampling Technique and Sample Size}

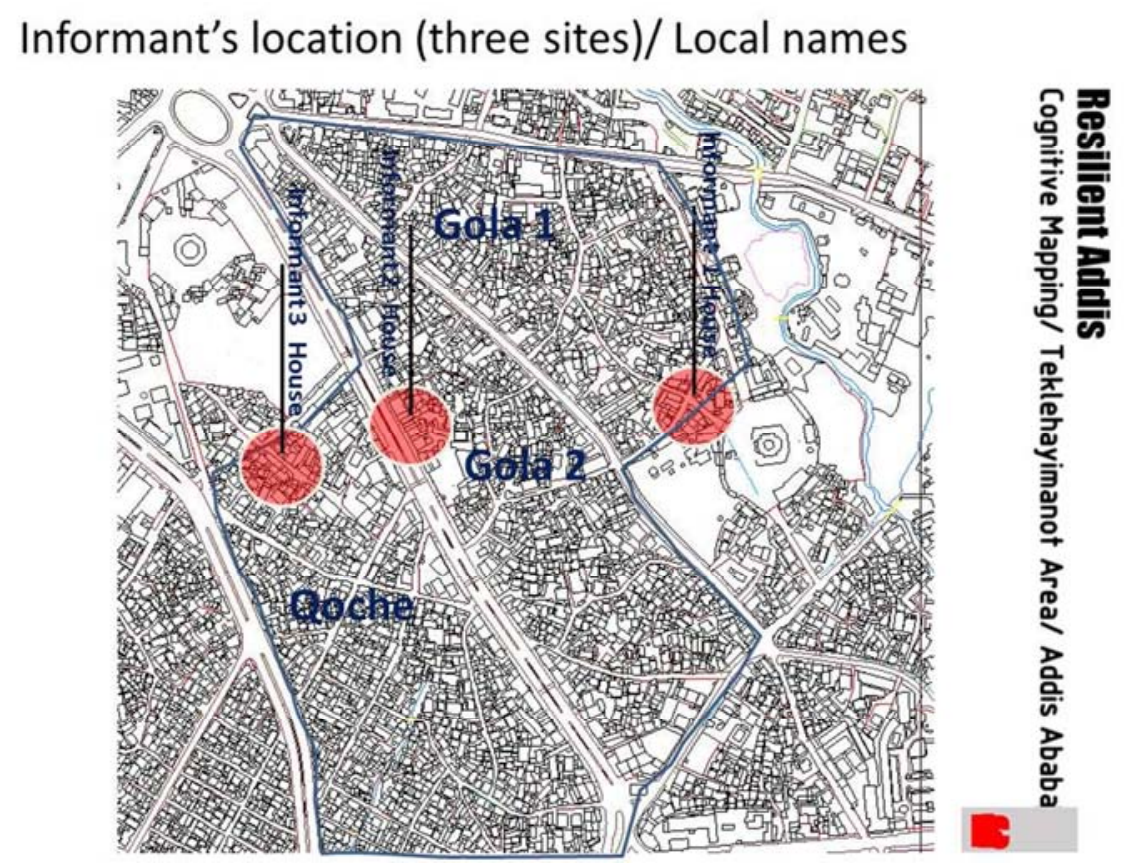

Figure 2. Randomly selected ongoing resilient areas. 


\section{Research Findings}

The research has the objective of describing the resilience of the study area with the aid of cognitive mapping portrayed by informants. On the onset of data gathering, the researcher has found informants using simple random sampling. Then after brief introduction about the researcher and the issue of the study, the informants were requested to provide their sketch map of their favorite and least favorite public spaces in their neighborhood. This is illustrated in the following map.
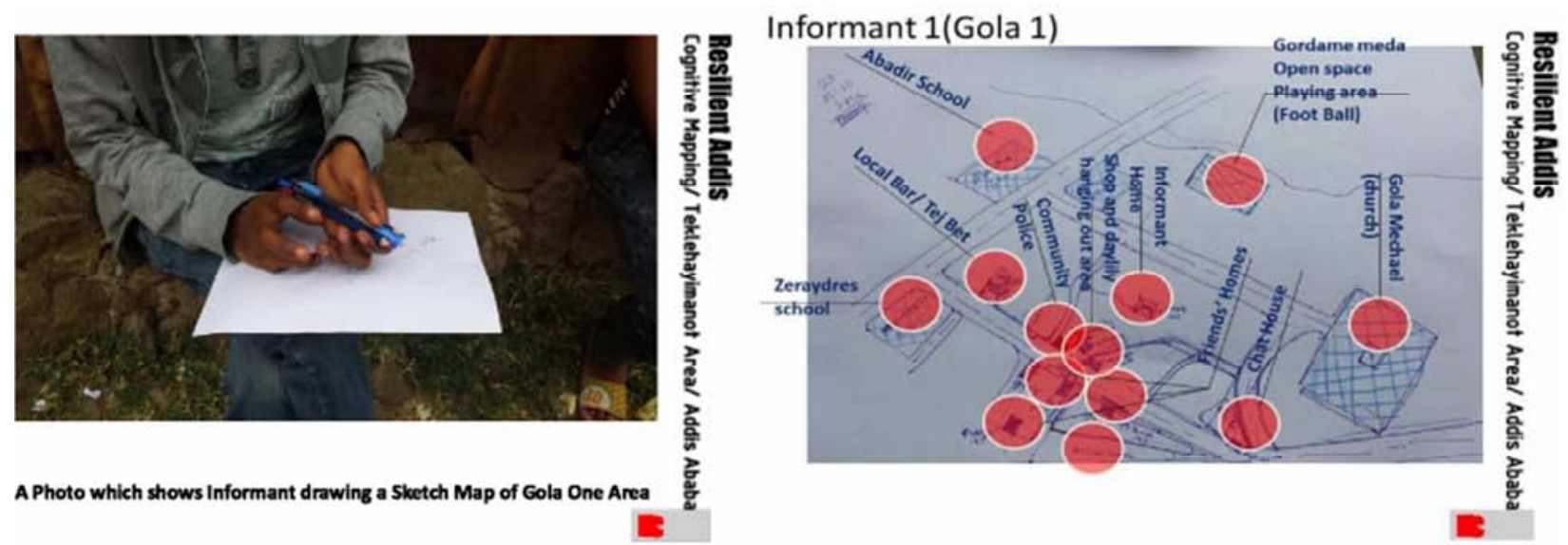

Figure 3. Photos and sketches (hand drawing) illustrating cognitive mapping in Gola One area.

In these sketches drawn by the first informant in Gola number one area, it is observed that the livability and resilience situation in the area is conducive for the informant. With this regards, the informant argued that the socioeconomic and ecological conditions and the living ways of the community is conducive to lead livable life. Furthermore, the respondent informed that the social, economic and environmental conditions in the study area are favorites for him to live in. Besides, the respondent argued that the community-policing center established in the area is not important. The respondent viewed the center as a tool for the government to deter and limit the freedom of residents especially the youngsters in terms of freedom of assembly, expression, and movement. The respondent regarded the center as his least favorite public place while the respondent viewed the open space reserved for football playing field as his most favored public area. For the informant, the football field is a good place to play football, conduct a hot discussion, and gathering with his friends in the morning and in the late evenings.

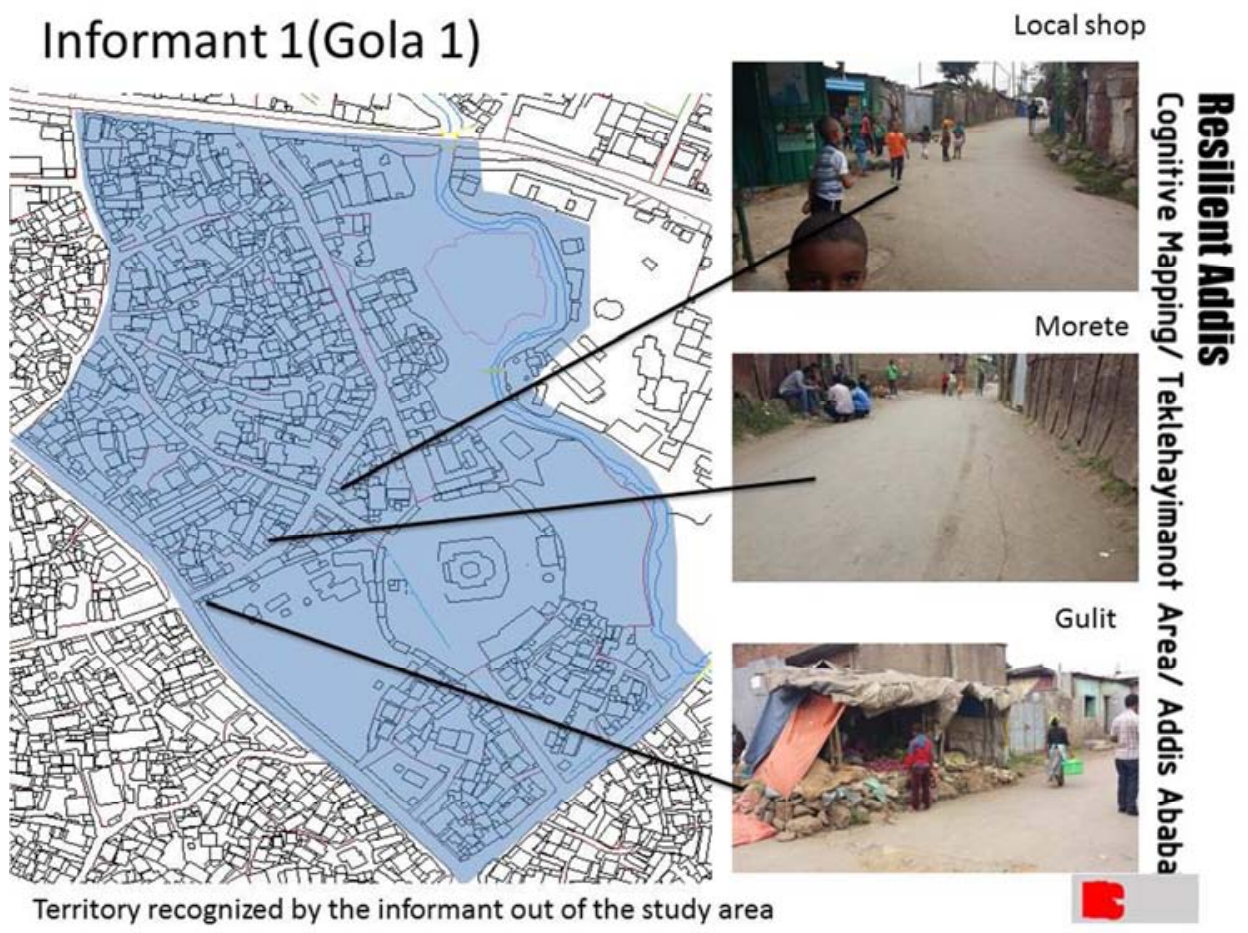

Figure 4. Demolished areas for resilience purpose in Gola One Area. 
The researcher viewed Gola One area differently, and argues that the area is not as conducive as the informant argued. Rather, the ecological and engineering aspect of the area is not conducive to lead a livable live. It is observed that there are no green areas in the study site. Houses are constructed in a compact situation. One school is situated in the middle of residential houses while the other school is compounded by highly polluted river.

This in turn may cause health damage to children who attend school. In addition, restaurants are mixed with resident houses of the community and other slum and mal-structured constructions are surfaced in the area. As it is indicated in a study conducted by Asian Development Bank in 2013 in Pacific region, urban resilience requires a move away from current reactive approaches and toward the development and implementation of effective urban planning and management systems to support better urban living standards. It further argued that to safeguard the health, environment and natural land of urban centers and improvements to urban quality of life, it is critical that cities are must consider these facet of resilience as integral parts of urban development planning. Besides, the researcher argues that the community-policing center located in the middle of Gola One is also situated in a proper place to keep the peace and security of the residents. In conclusion, it is argued by the researcher that in Gola One area there have to be a well-planned restructuring both in terms of ecological and engineering aspects to create a working resilience of the area. This will create a better livable environment for the residents of the study area [15].
Similarly advocates this, as it states the resilience of cities depends on the ability of the people and city planners to deal with environmental, social, economic, and psychological risk and to survive and thrive.

In the following sketch drawn by the second informant in Koche area, the resilience condition is almost similar with the conditions of the Gola area discussed in the above. The informant stated that the area that respondent lives in is under reconstruction process. New buildings, roads and other constructions are under process and replacing old and compacted constructions. With this regards, respondent argued that the re-construction process is demolishing the longstanding social and economic fabrics of the surrounding community. Besides, the old city in the area is conducive and livable for the people. Respondent pronounced that the old socio-economic and physical environment was a favorable situation while the current reconstruction is highly destabilizing peoples' living conditions. Furthermore, respondent stated that the compactness of residential houses, restaurants and business centers of the old city had significant social and economic benefits for the people. The respondent argued that household utilities, food items and other important facilities were easily accessible in nearby areas. Schools were close to resident houses and children did not go to fare areas to attend schools. However, after the old city is started to be reestablished, things are not as easy as before. The respondent stated that in order to get simple house.

\section{Informant 3/ Qoche}

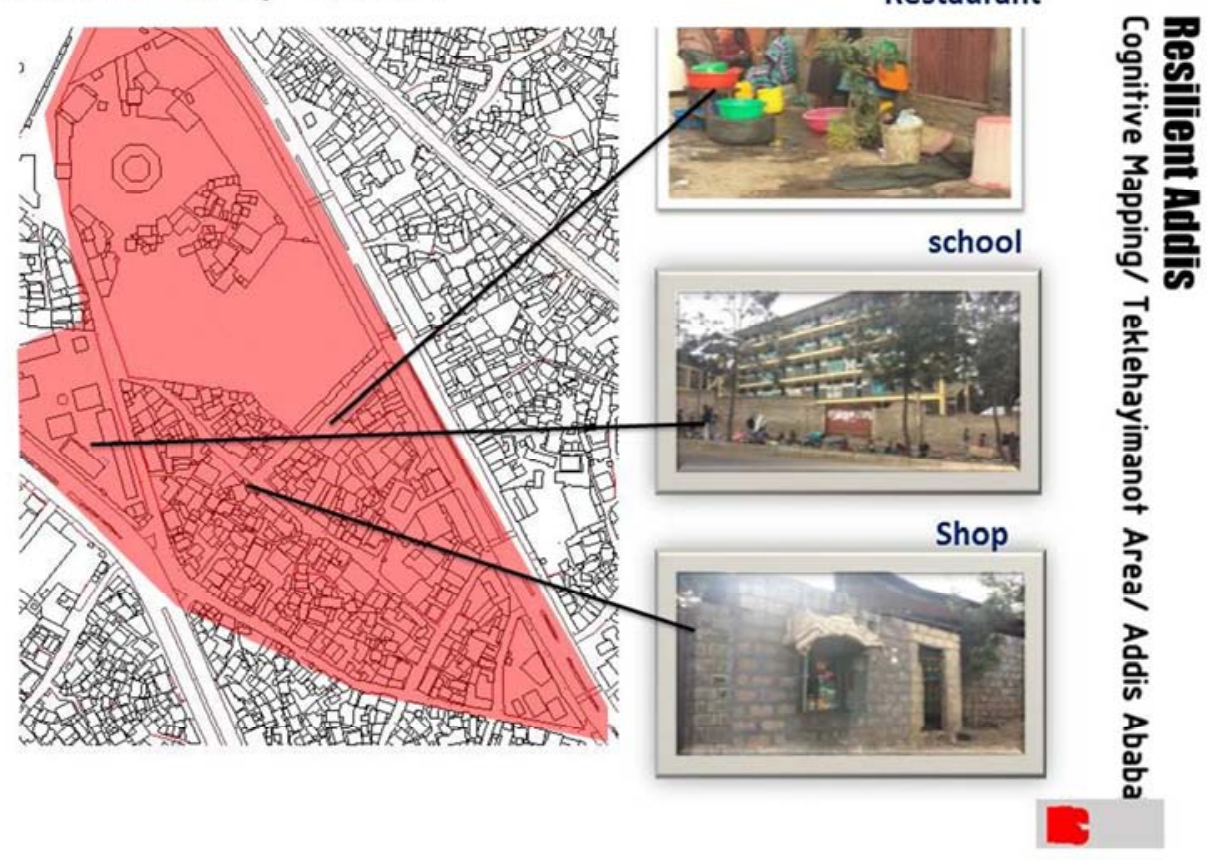




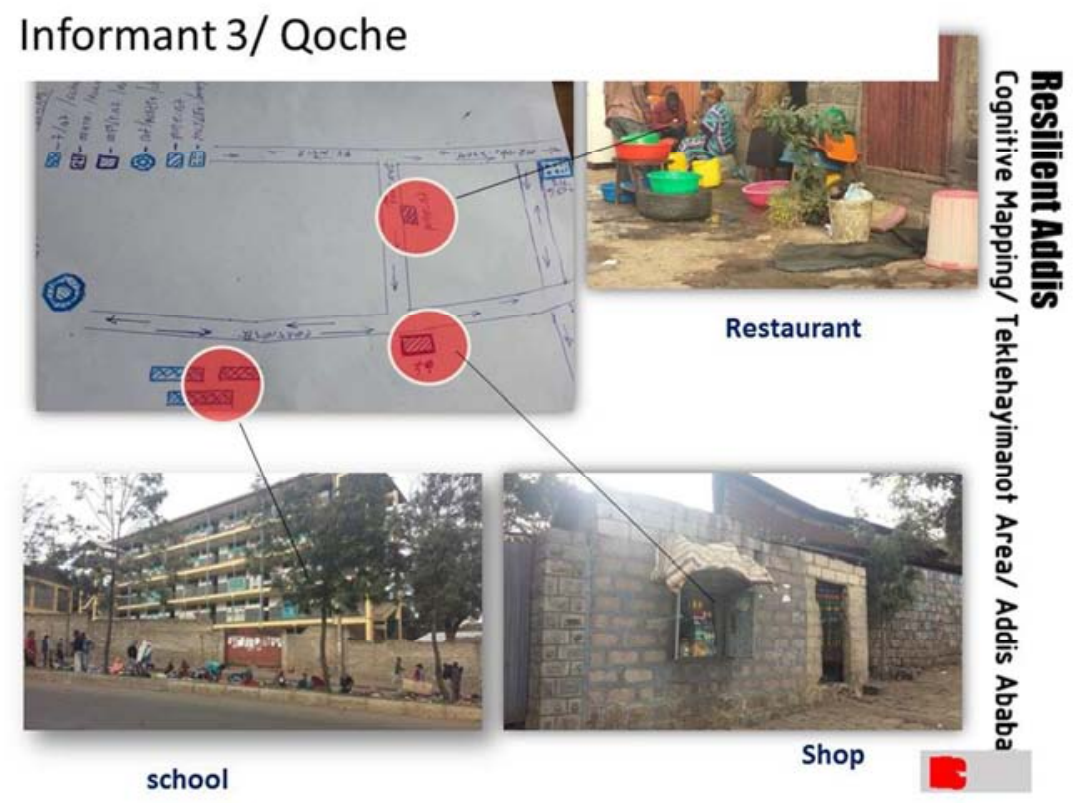

Figure 5. Cognitive Map drawn by informant 3 in Koche Area.

However, the researcher concluded that the resilience of the study area in its old pattern seem inappropriate and poorly planned. Although the informant argued against the re-construction of the area, the researcher has found that the re-construction process brings positive values for the community. It will benefit the community by providing a better access to improved roads, green areas, proper location of housing activities, schools, health centers, restaurants and other important public spaces. Similar to the researcher's view, the study conducted by the Ove Arup argues that the re-development of old and unplanned sites in cities within integrated mixed-use developments plans are extremely important. It provides better access to transport network, with many choices of route or safe and affordable modes, formal economic stability and planned residential sites with important services [14]. Besides, the researcher believes that the re-structuring process will also bring better environmental impact upon the surrounding as the demolished areas are newly established with improved environmental friendly building and constructions. Besides, the researcher argues that the re-construction process should take into consideration the socio-ecological perspectives of resilience as surrounding community value the social and economic aspects of their environment. Hence, it is advocated that the government efforts should be based on integrated development plan as it helps to tackle the legacy of unplanned city developments.

The third respondent from Gola Two site has tried to sketch the map in the following manner.

\section{Informant2/Gola 2}

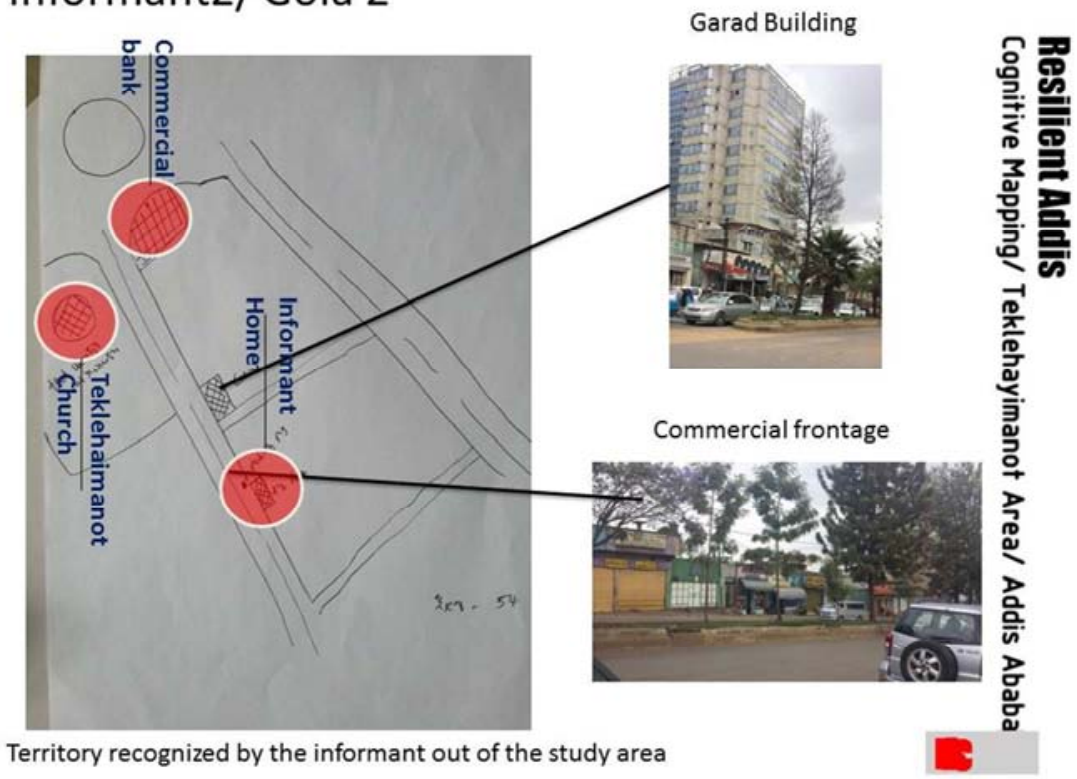




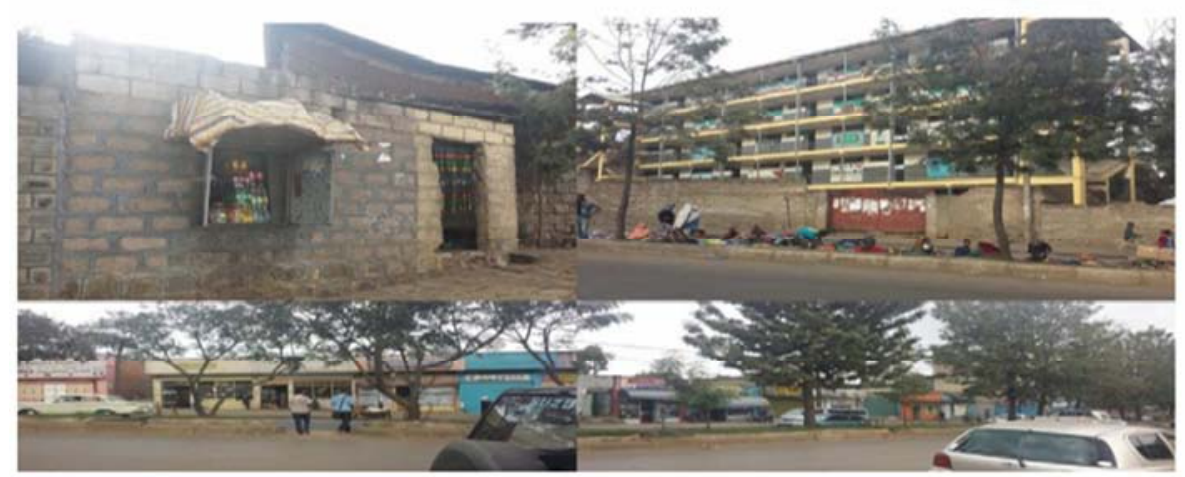

Figure 6. Cognitive Mapping drawn by of Informant 2 in Gola Two Sites.

The respondent argued that the compactness and densely constructed houses in the neighborhood are not standardized and create multiple vulnerabilities on the community. The informant has identified all aspect of the area settlement as his favorable places to live in except that the respondent dislikes the compactness residential houses and the fragmented and cracked down roads. The informant further argued that the government has started re-structuring roads, while some investments are operating to construct new buildings by replacing the existing old settlements; the Informant believes that this may harm the social bond of the community. The respondent pointed out that respondent needs the preservation of social and economic interactions of the existing system. As it is indicated in a study conducted by Wikström, in most cases urban resilience efforts are dominated by its environmental change aspects, and that social urban resilience is not yet a commonly used phrase within contemporary urban planning [1]. This implies that, by adapting some of the approaches used within environmental urban resilience when planning for social changes however, cities will be more resilient and be able to better identify, adapt to and improve the changing social patterns such as demographic changes and social exclusion [1, 14]. Hence, the researcher believes that similar to other sites of the study, this site also needs a holistic re-structuring to make it conducive and livable for the community. The researcher further argues that the direct observation to the site revealed that there are multiple social, economic and ecological urban problems exhibited in the area as the result of compactness of the housing, business and public areas. Hence, it is argued that the re-construction efforts started by different projects in the area need an integrated approach and considers the social, economic, and ecological conditions of the area so that it will be more resilient for the community. Besides, the level of resilience of the study areas is indicated in this study through the resilience indicators. With this regards, the following figures summarizes the discussion made in the above based on the major indicators of unban resilience. In the figures each indicators of resilience is illustrated through the photographs and cognitive mapping represented made by informants of the study. Finally, the resilience situation of the three sites is presented in the following sections.

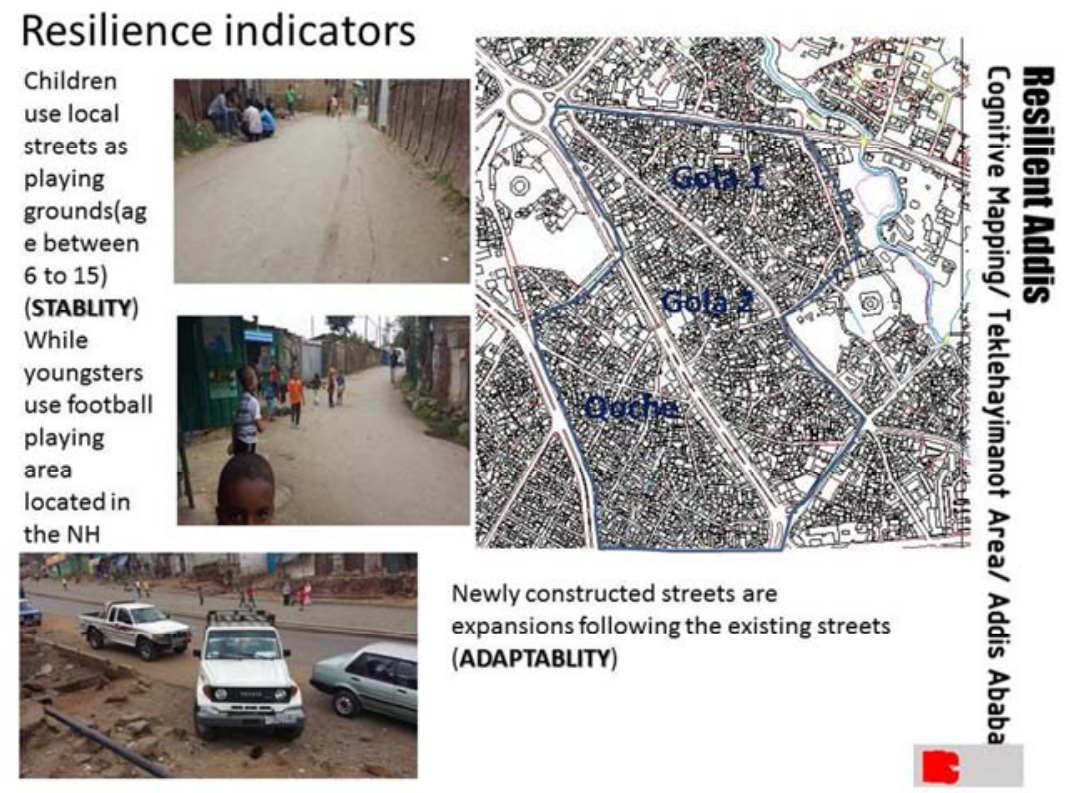



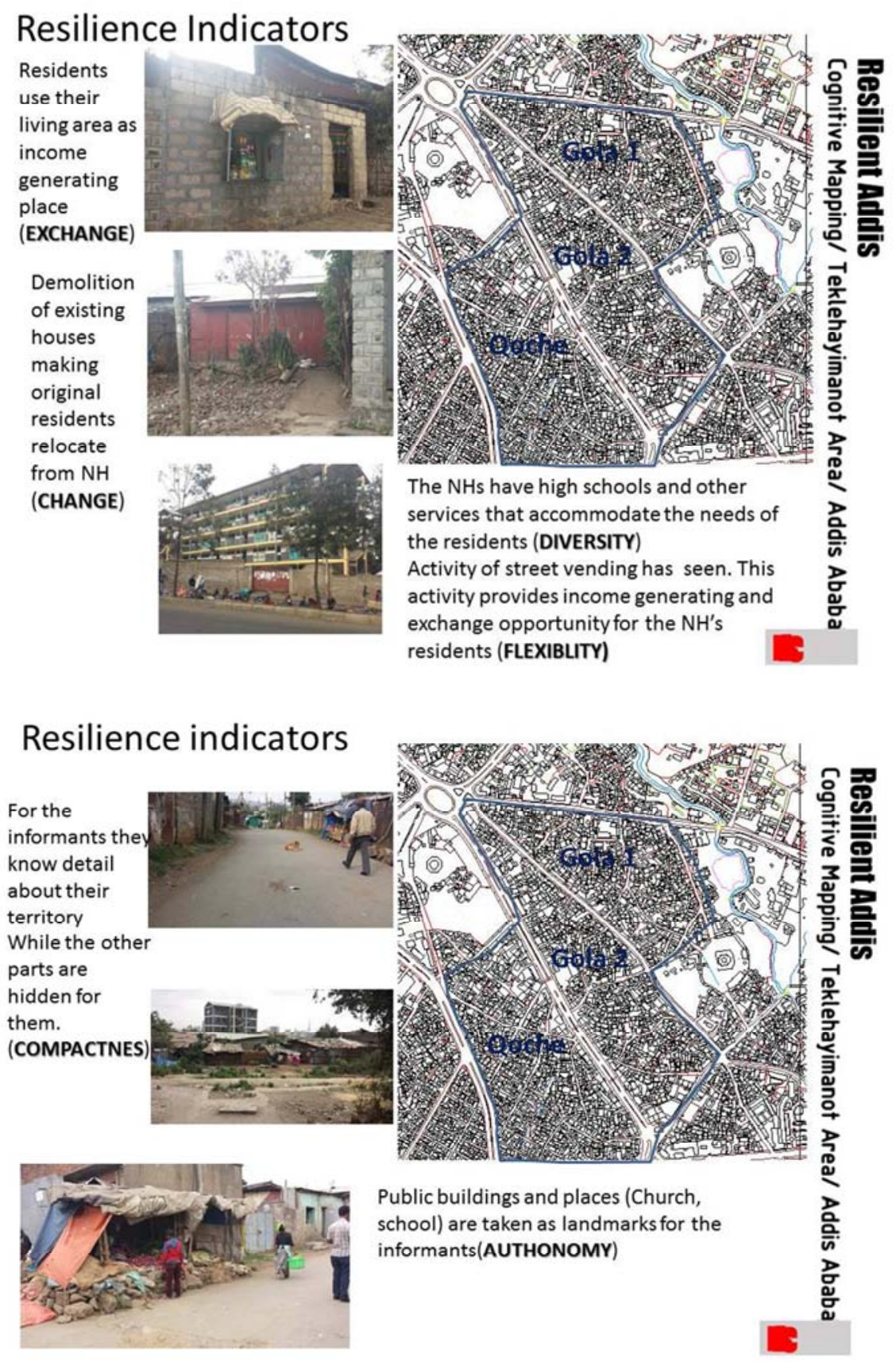

Figure 7. Application of resilience indicators in the study area.

\section{Conclusion}

In Ethiopia, it is estimated that about 20 per cent of the total population of the country currently lives in urban areas. In the past two decades, Addis Ababa has seen a tremendous urban expansion, which led the city into multifaceted socioeconomic and environmental problems. The city is experiencing a wide range of change in urban development aspects. The city administration expresses its efforts in establishing a more resilient city. However, different researchers argue that despite remarkable achievements in restructuring of the city to make it more livable, there are yet multiple urban problems and human vulnerabilities, which are exhibited in the city. With this regards, this miniresearch is conducted to investigate and analyze the resilience conditions of Teklahyimanot area of Addis Ababa city by gathering relevant data from randomly selecting respondents. The respondents are asked to portray their understanding of the situation in which they are living through the aid of cognitive mapping. The study revealed that respondents observe the social, economic and political change in their respective area closely. However, such urban changes are perceived in different ways based on the understanding of the respondents. Some of them consider the change as important for urban dynamic, which enhance the existed life conditions while others consider it as it can 
violate the freedom of the urban people. In general, the cognitive mapping portrayed by respondents from three different localities in Teklehyimanot area indicates that respondents are highly affiliated to the living condition they are leading. It indicates that the city administration efforts of re-structuring of the area must incorporate all dimensions of resilience, as the people are highly concerned about their compacted economic and social life. Besides, it is recommended that there are various instruments employed in understanding the urban change. If effective communication or awareness is prevailed concerning the urban resilience, it may have opportunities to manage the change in wellorganized manner and through formal instrument that could have improved social welfare in the study area. The different instrument employed to the urban change may affect the full impacts of the urban resilience. Therefore, the concerned government body and private sector should enhance the awareness of urban resilience of the communities and their effective instrument to enjoy the urban development endeavors.

Besides, as it is understood from the study, it is important for the government to adopt proper strategies in order to establish a more resilient urban development in the study area. These measures are illustrated in Ove Arup and Partners International Limited, as the strategy of city resilience in developing countries should focus on minimizing human vulnerability, diverse livelihoods and employment. It should also encompasses adequate safeguards to human life and health, collective identity and mutual support, social stability and security, availability of financial resources and contingency funds, reduced physical exposure and vulnerability, indicated by environmental stewardship; appropriate infrastructure; effective land use planning and enforcement of planning regulations.

\section{References}

[1] Wikström, Anna. 2013. "The Challenge of Change: Planning for social urban resilience: An analysis of contemporary planning aims and practices". Master's Thesis in Urban and Regional Planning, Department of Human Geography, Stockholm University, 2013. Available on: www.humangeo.su.se
[2] World Bank. 2012. "Building Urban Resilience: Principles, Tools and Practice". World Bank Group 1818 H Street, NW Washington, DC, USA, 2012.

[3] Ove Arup and Partners International Limited. 2014. City Resilience Framework: City Resilience Index. Rockefeller Foundation.

[4] Godschalk, David R. 2003. "Urban Hazard Mitigation: Creating Resilient Cities". Natural Hazards Review, ASCE.

[5] Ministry of Urban Development, Housing and Construction. 2014. "National Report on Housing \& Sustainable Urban Development". Addis Ababa, Ethiopia.

[6] Office for the Revision of Addis Ababa Master Plan. The Revision of Addis Ababa Master Plan. 2001. Addis Ababa, Ethiopia.

[7] Alebe Bayrau and Genanew Bekele. 2007. "Investors' Willingness to Pay for Urban Land: The Case of Addis Ababa City. Western Michigan University, Kalamazoo, USA.

[8] Meheret Ayenew. 1999. "The City of Addis Ababa: Policy Options for the Governance and Management of a City with Multiple Identity". FSS Discussion Paper No. 2, Addis Ababa University, Ethiopia.

[9] Williams, Yolanda. 2015. "Cognitive Map: Definition and Examples". Available on: Cognitive mapping 2/cognitivemap-definition-and-examples. html. Assessed on 26/12/2015.

[10] Davis, Diane E. and John Tirman. 2012. "Urban Resilience in Situations of Chronic Violence". Woodrow Wilson Center, Comparative Urban Studies Program, Harvard University, Center for International Studies.

[11] World Bank Group. 2017. Safe and Resilient Cities in Ethiopia city strength Diagnostics in nine Regional Capitals and Dire Dawa City Administration. Addis Ababa, Ethiopia.

[12] World Bank Group. 2015. Enhancing Urban Resilience. USA, Washington, $D C$.

[13] United Nations Human Settlements Programme (UN- Habitat). 2017. The State of Addis Ababa. Nairobi, Kenya.

[14] Kothari, C. R. 2004. "Research Methodology-Methods and Techniques". New Delhi, Wiley Eastern Limited. Liao,

[15] Davis, Diane E. 2012. "Urban Resilience in Situations of Chronic Violence". Final Report, Massachusetts Institutes of Technology, USA. 